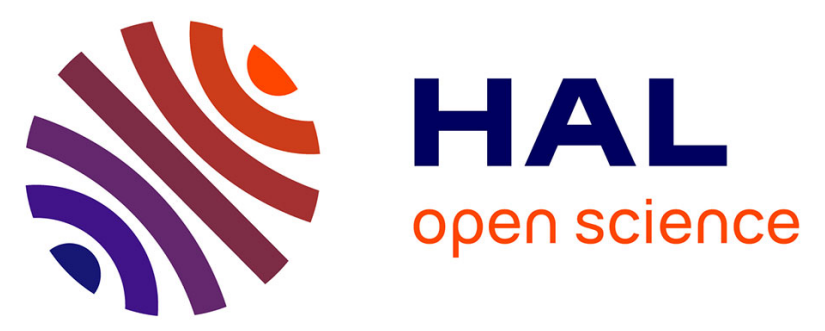

\title{
Adoption of Sharing Economies of Communitive Consumption Providing an Exchange of Services: A Conceptual Frame Work
}

\author{
Zainah Qasem, Raed Algharabat, Ali Abdallah Alalwan
}

\section{To cite this version:}

Zainah Qasem, Raed Algharabat, Ali Abdallah Alalwan. Adoption of Sharing Economies of Communitive Consumption Providing an Exchange of Services: A Conceptual Frame Work. International Working Conference on Transfer and Diffusion of IT (TDIT), Jun 2018, Portsmouth, United Kingdom. pp.90-101, 10.1007/978-3-030-04315-5_7 . hal-02068946

\section{HAL Id: hal-02068946 \\ https://hal.inria.fr/hal-02068946}

Submitted on 15 Mar 2019

HAL is a multi-disciplinary open access archive for the deposit and dissemination of scientific research documents, whether they are published or not. The documents may come from teaching and research institutions in France or abroad, or from public or private research centers.
L'archive ouverte pluridisciplinaire HAL, est destinée au dépôt et à la diffusion de documents scientifiques de niveau recherche, publiés ou non, émanant des établissements d'enseignement et de recherche français ou étrangers, des laboratoires publics ou privés. 
Adoption of Sharing Economies of Communitive Consumption Providing an Exchange of Services: A Conceptual Frame Work

\title{
'Zainah Qasem, Raed Algharabat ${ }^{2}$ Ali Abdallah Alalwan ${ }^{3,}$
}

${ }^{1}$ The School of Business Department of Marketing, The University of Jordan, Amman, Jordan

z.qasem@ju.edu.jo

${ }^{2}$ The School of Business Department of Marketing, The University of Jordan, Amman, Jordan

r.gharabat@ju.edu.jo

${ }^{2}$ Amman College of Banking and Finance, Al-Balqa' Applied University, Amman, Jordan alwan.a.a.ali@gmail.com

\begin{abstract}
Over the past decade many successful and fast-growing businesses, such as Airbnb, Uber, DogVacy, RelayRides, TaskRabbit, have developed. What these businesses have in common were their underlying business models which are the sharing economies of communitive consumption. Consequently, understanding what kind of communitive consumption services are customers willing to participate in, and examining factors that shape customers attitude towards $\mathrm{CC}$ and eventually intention to engage with communitive consumption in an online context is very important for practitioners, customers, and policymakers alike. Our intention in this paper is to present a conceptual framework that offers an understanding of factors affecting consumers' attitudes and intentions towards adopting communitive consumption platforms. However, our focus will be directed towards communitive consumption platforms which provide services with direct relationship and effect on property and individuals with sentimental value to communitive consumption user such as pets. To achieve our goal of understanding consumer adoption of communitive consumption we provided a theoretical foundation for discussion and future research about these new, alternative consumption modes by proposing a series of testable research propositions; which we intend developing into empirical studies.
\end{abstract}

Keywords: Social commerce, sharing economies of collaborative consumption (CC), Social exchange theory 


\section{Introduction}

Over the past decade, many successful and fast-growing businesses, such as Airbnb, and Uber, have developed. What these businesses have in common were their underlying business models which are based on the sharing economies of collaborative consumption (CC) and "collective exchange", by which many customers access goods and services that are provided by a peer (Botsman and Rogers, 2010; Benoit et al., 2017).

PwC research estimates that the total transactions for the four sectors dominated by CC (accommodation, transport, crowdfunding and lending, skilled or unskilled labour) in Europe, is valued at $€ 28$ billion in 2016 , will see a 20 -fold increase to $€ 570$ billion by 2025 (PwC, 2017). Having this said, there is probably a span of taking a ride by Uber, via renting out our apartment via Airbnb, to let someone unknown be a babysitter for our kids. The sentimental value of object involved in the relationship between service provider and receiver is expected to play a significant role in shaping this relationship. Consequently, understanding what kind of communitive consumption services are customers willing to participate in, and examining factors that shape customers attitude towards CC and eventually intention to engage with $\mathrm{CC}$ in an online context is very important for practitioners, customers, and policymakers alike (Hamari et al., 2015).

Further, the shift towards favouring product ownership, the increasing interest in understanding the societal impact of consumption (Schor and Fitzmaurice, 2015), and the burgeoning digital platform and consumer eagerness to use mobile applications facilitated peer-to-peer business models and introduced $\mathrm{CC}$ as an alternative for consumers (Yaraghi and Ravi, 2017). Thus, CC is expected to have a significant societal impact and results in a potential alteration in e-commerce patterns and impact on online sales.

Our intention in this paper is to present a conceptual framework that offers an understanding of factors affecting consumers' attitudes and intentions towards adopting CC platforms. However, our focus will be directed towards CC platforms which provide services with direct relationship and effect on property and individuals with sentimental value to $\mathrm{CC}$ user such as pets.

\section{Literature review}

\subsection{Social commerce}

Social commerce is a form of Internet-based activities that depend on peer-to-peer interaction, and it utilises social media to "support social interactions and user contributions to assist activities in the buying and selling of products and services online and offline" (Wang and Zhang, 2012, p. 2). Similarly, Yadav et al. (2013) defined social commerce as an "exchange-related activities that occur in, or are 
influenced by, an individual's social network in computer-mediated social environments, where the activities correspond to the need recognition, pre-purchase, purchase, and post-purchase stages of a focal exchange" (Yadav et al., 2013, p312).

In view of this, social commerce is associated with exchange-related activities which include, but not limited to, transaction, and computer-mediated social environment that encompass activities related to both consumer and companies contained under social commerce domain (Huang and Benyoucef, 2017).

Taking into consideration social commerce definition and main associations, CC, - "an economic system in which assets or services are shared between private individuals, either free or for a fee, typically by means of the Internet" (Oxford, 2017), is categorised a form of social commerce.

\subsection{Sharing economies of collaborative consumption (CC)}

$\mathrm{CC}$ is acknowledged as an emerging trend that is altering consumer behaviour in the twenty-first century (Economist, 2013). Hamari et al. (2015) formed a holistic definition to $\mathrm{CC}$ by combining previous knowledge about $\mathrm{CC}$ and the mapping of 254 $\mathrm{CC}$ websites. Their definition suggested that $\mathrm{CC}$ is "a peer-to-peer-based activity of obtaining, giving, or sharing the access to goods and services, coordinated through community-based online service" (Hamari et al., 2015, p1).

Based on Hamari et al. (2015) definition, CC practices are sharing two commonalities. First, is their dependence on the internet, and second is their reliance on non-ownership models using consumer goods and services (Botsman and Rogers, 2010; Kaplan and Haenlein, 2010; Wang and Zhang, 2012; Belk, 2014). The latter argument suggests that $\mathrm{CC}$ will result in a shift in consuming culture from a culture of owning towards a culture of sharing. It also indicates that this shift is motivated and driven by peer-to-peer internet platforms which link consumers and allow them to make more efficient use of underutilised assets (Martin, 2016). However, there has been much less research examining variable affecting people

decision to adopt CC.

Never the less, CC is considered an umbrella concept that includes many information and communication technology developments which endorses sharing the consumption of goods and services through online platforms (Botsman and Rogers, 2010). Schor and Fitzmaurice (2015) suggested that the there are four main categories that $\mathrm{CC}$ consumption goes under-re-circulation of goods, optimising the use of assets, building social connections and exchange of services. This paper's primary focus is on understanding consumer adoption of $\mathrm{CC}$ providing an exchange of services.

\subsection{Sharing economies of collaborative consumption providing an exchange of services}

Sharing economies which focus on providing an exchange of services is not a new concept to the market of services (e.g. Time-banks). However, the growing desire for 
communal consumption, and the widespread of collaborative web communities; led to the reintroducing of the concept (Schor and Fitzmaurice, 2015). The market has many peer-to-peer platforms that are serving as CC providing an exchange of services in different domains, including but not limited to, hospitality service, delivery of passengers, and pet fostering. These platforms are considered a $\mathrm{C} 2 \mathrm{C}$ sharing platforms that are often being facilitated by an external provider like an online platform. The market has many successful companies and platforms that are providing access to $\mathrm{CC}$ that provides services (e.g. CouchSurfing, Uber, and Dogvacay).

When observing platforms separately, each platform provides a service that targets products and individuals with different level of sentimental value to $\mathrm{CC}$ users.

\subsection{Products and property perceived value}

Product perceived value is a subjective construct that varies between customers, cultures, and times (Sa'nchez et al., 2006). People tend to evaluate product perceived value based on their functionality; emotional functionality and utilitarian functionality (Burns and Evans, 2000). Emotional functionality refers to "the experience of an emotional bond with a product, which implies that a strong relationship or tie exists between an individual and an object" (Muggea et al. 2009, p467).

Perceived emotional values are a matter of degree. For example, jewellery is expected to have a higher sentimental value than a kitchen tool (McDonagh et al., 2002). When a person perceives an object as high in emotional value, the person will develop an emotional attachment to the product - an emotional target-specific bond between a person and a specific object (Bowlby, 1979). As a result, the object will acquire a meaning beyond functional meaning and becomes an extraordinary object.

Overall, being attached to a specific product will generate positive emotions such as happiness, love, warmth, and pride towards the object (Schultz et al. 1989). Hence, people will start to cherish their relationship with the product and show protective behaviour towards it (Muggea et al. 2009).

Previous studies suggests that people can form emotional attachments to a variety of objects including (pets, places, and celebrities) (Shimp and Madden, 1988; AdamsPrice and Greene, 1990; Alperstein, 1991; Rubinstein and Parmelee, 1992; Hirschman, 1994; Sable, 1995; as cited by Thomson et al., 2005).

CC emerged from many technological developments that have facilitated the sharing of tangible and intangible products using different Internet-based IT systems (Hamari et al., 2015). Therefore, this paper will look at CC as an information and communications technology. As a result, the literature on technology acceptance will provide a theoretical background for this paper.

\section{Theoretical background}

The theoretical foundations for the acceptance models encompass many models that are related to information systems. For example, the original technology acceptance model (TAM) (Davis, 1986; Davis et al., 1989) and its models derived from TAM such as UTAUT and UTAUT2 (Venkatesh et al., 2003; Venkatesh et al., 2012 ). It also includes theories that are borrowed from other disciplines and adapted 
to information system disciplines such as the Innovation Diffusion Theory (Matzner et al., 2015) and Social exchange theory (SET) (Emerson, 1976). The model we propose is based on the SET as a theoretical foundation and will incorporate constructs from UTAUT2.

\subsection{The unified theory of acceptance and use of technology (UTAUT)}

UTAUT was developed by Venkatesh et al. (2003) as a holistic model that incorporates constructs from eight different theories and proposes an understanding of new technology adoption. UTAUT consists of four fundamental variable performance expectancy, effort expectancy, social influence, and facilitating conditions and four moderating variables gender, age, experience, and voluntariness of use (Venkatesh et al.,2003.) UTAUT was extended to accommodate for consumer use setting by integrating hedonic motivation, price, and habit . The extended UTAUT (UTAUT2) suggest that in the context of consumer use of information technology, both utilitarian benefits and hedonic benefits are considered vital factors of technology use Vankatesh et al. (2012)

\subsection{Social exchange theory (SET)}

SET postulates that human relationships are formed by the use of a subjective costbenefit analysis and the comparison of alternatives (Emerson, 1976). Thus, SETs central proposition is that individuals intend to choose the relationship that maximises their benefits. SET has been extensively adopted as one of the most significant theories to explain social interaction information systems and served as a theoretical framework which can sufficiently reflect the characteristics of CC such as peer-topeer relationships (Stafford 2008; Chen 2013 as cited by Kim et al., 2015).

Consumers' assessment of benefit and cost indicates a proactive cost-benefit analysis. In this paper, we suggest that consumer benefit comprise constructs that were examined by previous studies and reported to motivate consumers to engage in $\mathrm{CC}$ these are: enjoyment of using the system, social benefit, and cost-benefit (Hamari et al., 2015). On the other hand, the cost of the consumer is the perceived risk related to trust

\section{Research model and hypothesis development}

\subsection{Attitude}

Attitude is "an individual's positive or negative feelings (evaluative affect) about performing the target behaviour" (Fishben and Ajzen, 1975, p. 216). Attitudes definition suggests a relationship between attitude and behaviour. Thus we hypothesise that

H1: there is a positive relationship between attitude and behaviour in $\mathrm{CC}$ that provides a service involved with the product with sentimental value. 
However, in CC, there is an assumption that these two constructs are not necessarily related. Therefore, there is a need to study consumer relationship with them separately (Hamari et al., 2015). This discrepancy is attributed to consumer analysis of benefit and cost relationship which might lead to a different behaviour than the one expected to match with the attitude.

\subsection{Enjoyment of using the system}

Perceived enjoyment is an important dimension of intrinsic motivator defined as "the extent to which the activity of using the computer is perceived to be enjoyable in its own right" (Davis et al., 1992, p. 1113). Enjoyment has been the focus of many studies interpreting Internet and Communication Technologies acceptance and sharing related activates (Van der Heijden, 2004).

Hwang and Griffiths (2017) reported a positive relationship between hedonic factors (e.g. enjoyment) and attitude towards online shopping. In the CC context, Hamari et al. (2015) have also reported a positive relationship between enjoyment and attitude and behaviour.

Similarly to previous studies, we are proposing that in the context of CC providing an exchange of service to property and individuals with sentimental meaning, people will engage in this activity for what is beyond utilitarian value, such as meeting people who share the same hobby (e.g. collectors and pet owners). Therefore, we propose incorporating enjoyment into our model as an intrinsic factor.

$\mathrm{H} 2 \mathrm{a}$ : Perceived enjoyment from participating in CC platforms positively influences attitude towards $\mathrm{CC}$ that provides a service involved with the product with sentimental value.

$\mathrm{H} 2 \mathrm{~b}$ : Perceived enjoyment from participating in $\mathrm{CC}$ platforms positively influences attitude towards $\mathrm{CC}$ that provides a service involved with the product with sentimental value.

\subsection{Economic benefits}

A previous study by Hennig-Thurau et al. (2007) endorsed that consumers are significantly attracted by $\mathrm{CC}$ when they recognise earning more benefits when using it in comparison to the cost. Tussyadiah and Pesonen (2015) stated that CC is an attractive substitute for consumers due to its economic benefits (i.e. low cost), which was considered necessary after the global financial crisis. Hence we are proposing to incorporate economic benefit as an influencer of attitude.

$\mathrm{H} 3 \mathrm{a}$ : Perceived economic benefits from participating in $\mathrm{CC}$ positively influences attitude towards $\mathrm{CC}$ that provides a service involved with the product with sentimental value.

$\mathrm{H} 3 \mathrm{~b}$ : Perceived economic benefits from participating in $\mathrm{CC}$ positively influences behaviour towards $\mathrm{CC}$ that provides a service involved with the product with sentimental value. 


\subsection{Social benefit}

The context of CC is characterised as a philanthropic context. Batson (1998) defines philanthropy as "actions intended to benefit one or more people other than oneself” (Batson, 1998, p. 282). Bullard and Penner (2017) argued that making an impact in the lives of others by giving up one's own personal resources (e.g., money, time) is a fundamental part of philanthropic behaviour. However, economic theory of maximising behaviour and rational choice suggests that people do not view giving up resources as a desired behaviour (Crocker and Linden, 1998). Relatedly, the perceived impact has been recognised as a psychological instrument that endorses philanthropic giving (Erlandsson et al., 2015; Bullard and Penner, 2017). Accordingly, individuals are more willing to engage in an activity if they perceive that they can make a significant impact with their actions. Thus, social benefit - as an outcome of philanthropic behaviour- is assumed to have a role in shaping consumer attitude and behaviour towards CC.

People are reported to participate in activities that involve sharing, and helping others driven by an obligation to do good for other people (Prothero et al., 2011). Therefore, believing in the importance of getting involved in online platforms as a mean to support the community is expected to influence people attitude and behaviour towards adopting the use of $\mathrm{CC}$ that provide a service involved with the product with sentimental value.

$\mathrm{H} 4 \mathrm{a}$ : Social benefit positively influences attitude towards $\mathrm{CC}$ that provides a service involved with the product with sentimental value.

$\mathrm{H} 4 \mathrm{~b}$ : Social benefit positively influences behaviour towards $\mathrm{CC}$ that provides a service involved with the product with sentimental value.

\subsection{Trust}

Trust has always been an important factor in online communication and usage. Mayer et al. (1995) defined trust as "the willingness of a party to be vulnerable to the actions of another party based on the expectations that the other party will perform a particular action important to the trustor, irrespective of the ability to monitor or control that other party" Mayer et al. (1995, p. 172)

Owyang (2013) proposes numerous challenges related to CC concept. Lack of trust between peer-to-peer users and lack of reputation and standard are some of these challenges. Mistrust among strangers and concerns for privacy were suggested as trust related issues that form barriers and affect $\mathrm{CC}$ (Olson, 2013).

A very recent study by Mittendor (2018) found evidence that trust in the intermediary' and 'Trust in providers' are decisive for the obtainers' intentions on the online platform. Using and adopting CC implies a certain level of trust (Botsman and Rogers, 2010), for example, giving a product with sentimental value like your pet contains high risk. Thus, we propose that.

H5a: Trust has a positive relationship towards attitude in $\mathrm{CC}$ that provides a service involved with the product with sentimental value.

$\mathrm{H} 5 \mathrm{~b}$ : Trust has a positive relationship towards behaviour in $\mathrm{CC}$ that provides a service involved with the product with sentimental value. 


\subsection{Technology}

Finally, the CC is an Internet and Communication Technology. Therefore, it can be influenced by the characteristics of the technology. For example, Chong et al. (2009) suggested that ease of use, complexity and trainability of the technology systems has a vital role in predicting adoption of online platforms that allow multiple users to interact, collaborate, and transact with each.

Comparably, consumers are believed to adopt CC if they perceive the technology systems effortless and easy to use. Therefore, we propose that

H6a: effort expectancy positively influences attitude towards $\mathrm{CC}$ that provides a service involved with the product with sentimental value.

H6b: effort expectancy positively influences behaviour towards CC that provides a service involved with the product with sentimental value. 


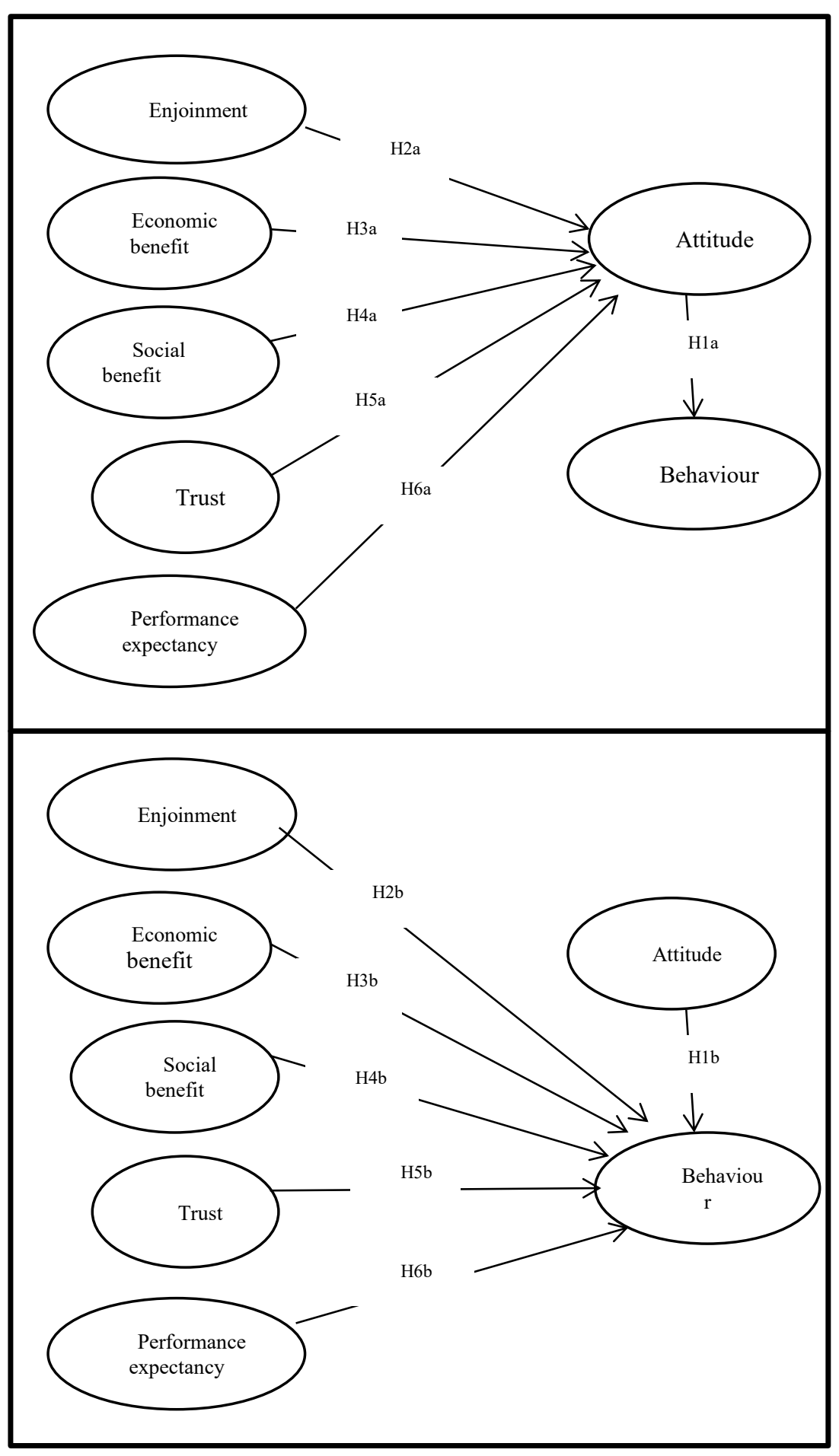




\section{Proposed Research Methodology}

As discussed above, the current study model and research hypotheses were proposed based on two models that explain consumer adoption behaviours of new technology (UTAUT and SET). The targeted context of this study will be people who use $\mathrm{CC}$ to receive services that are concerned with properties and individual with sentimental value. Consumer research suggests that people can form emotional attachments to a variety of objects, including pets (Thomson et al., 2005). Therefore, we are proposing developing a survey based quantitative research which will be allocated to actual users of DogVacy as an example of CC platforms that are providing service involved with a product with sentimental value, and pet owner as potential users of such as platforms.

Factors will be measured using scale items adopted and adapted when necessary from previous studies that have measured proposed items in online context. To measure attitude we will use a five-item scale adapted from Ajzen (1991). To measure behaviour, we will use a four-item scale adapted from Bhattacherjee (2001). To measure enjoyment we are using a five-item scale adapted from van der Heijden (2004). To measure economic benefit we are using a four-item scale adapBock et al. (2005). To measure performance expectancy, we are using a five-item scale adapted from Venkatesh et al.2003. To measure trust, we are using a four-item scale adapted from Corritore et al. (2005). To measure we are using a four-item scale adapted from social benefit Barnes and Mattsson (2017).

Once the data is collected, a structural equation modelling analysis will be conducted to validate the conceptual model and verify the significance of the hypothesis

\section{Conclusion and Future work}

The rapid change in consumer attitudes towards product ownership and the societal impact of consumption (Schor and Fitzmaurice, 2015), technology progression (Botsman and Rogers, 2010), and a desire for communal consumption have created a shift of attitudes towards consumption in general, and put more importance on sharing economies as an alternative for consumers (Hamari et al., 2015; Cheng, 2016). Altogether, has brought great importance to understanding what influences consumers to adopt $\mathrm{CC}$.

There are different categories that CC consumption goes under-re-circulation of goods, optimising the use of assets, building social connections and exchange of services (Schor and Fitzmaurice, 2015). However, our primary concern is CC providing an exchange of services. Specifically, services that target products and individuals with sentimental value to consumers (e.g. pet caring and fostering, babysitting, and jewellery exchange).

To achieve our goal of understanding consumer adoption of CC we provided a theoretical foundation for discussion and future research about these new, alternative 
consumption modes by proposing a series of testable research propositions; which we intend developing into empirical studies.

\section{References}

1. Adams-Price, C.Greene, A. L. 1990. Secondary attachments and adolescent self-concept. Sex Roles.22.Pp: 187-198.

2. Alperstein, N. M. 1991. Imaginary social relationships with celebrities appearing in television commercials. Journal of Broadcasting and Electronic Media. 35.Pp: 43-58

3. Alsever, J. 2013. The "mega trend" that swallowed Silicon Valley. CNN Money. [Online] [Accessed 9/2/2018]. Available on the World Wide Web at: http://tech.fortune.cnn.com/2012/10/03/themega- trend-that-swallowed-silicon-valley/

4. Barnes, S. Mattsson, J.2017. Understanding Collaborative Consumption: Test of a Theoretical Model. Technological Forecasting and Social Change. 118. P. 281-292

5. Batson, C. D. (1998). Altruism and prosocial behavior. In D. T. Gilbert, S. T. Fiske, \& G. Lindzey (Eds.), Handbook of social psychology. Boston: McGraw-Hill

6. Belk, R. 2014. You are what you can access: Sharing and collaborative consumption online. Journal of Business Research. 67(8).Pp: 1595- 1600.

7. Benoita, S. Bakerb, T. Boltonc, R. Gruberd, T. Kandampully, J. 2017. A triadic framework for collaborative consumption (CC): Motives, activities and resources and capabilities of actors. Journal of Business Research. 79. Pp: 219-227

8. Botsman, R.Rogers, R. 2010. What's mine is yours: The rise of collaborative consumption. New York, NY: Collins.

9. Bowlby, J. 1979. The making and breaking of affectional bonds. London: Tavistock.

10. Bullard, O. and Penner, S. 2017. A regulatory-focused perspective on philanthropy: Promotion focus motivates giving to prevention-framed causes. Journal of Business Research.79.P.173-180

11. Burns, A.D., Evans, S., 2000. Insights into customer delight. In: Scrivener, S.A.R., et al. (Eds.), Collaborative Design; Proceedings of CoDesigning 2000, UK, 11-13 September, Springer, London, pp. 195-203. ISBN 1-85233-341-3.

12. Chen, R. 2013. Member use of social networking sites - An empirical examination. Decision Support Systems. 54(3). Pp: 1219-1227

13. Cheng, M. 2016. Sharing economy: A review and agenda for future research. International Journal of Hospitality Management. (57), Pp: 60-70.

14. Chong, A. Y.-L., Ooi, K.-B., \& Sohal, A. (2009). The relationship between supply chain factors and adoption of e-collaboration tools: An empirical examination. International Journal of Production Economics 122(1): 150-160.

15. Davis, F.D. Bagozzi. P. Warshaw.R. 1992. Extrinsic and intrinsic motivation to use computers in the workplace. Journal of Applied Social Psychology. 22(14). Pp: 1111-1132.

16. Davis, F. Bagozzi, R. Warshaw, P. 1989. User Acceptance of Computer Technology: A Comparison of Two Theoretical Models. Management Science. 35 (8).Pp: 982-1003.

17. Davis, F. 1986. A Technology Acceptance Model For Empirically Testing New End-User Information Systems: Theory and Results. Ph.D. Thesis. Massachusetts Institute of Technology.

18. Emerson, R. 1976. Social Exchange Theory. Annual Review of Sociology. 2.Pp: 335-362

19. Erlandsson, A., Björklund, F., \& Backström, M. 2015. Emotional reactions, perceived impact and perceived responsibility mediate the identifiable victim effect, proportion dominance effect and in-group effect, respectively. Organizational Behavior and Human Decision Processes, 127(1), 1-14. 
20. Fishbein, M.. Ajzen, I. 1975. Belief, attitude, intention, and behaviour: An introduction to theory and research. Reading, MA: Addison-Wesley.

21. Hamari, J. Sjöklint, M. Ukkonen,A.2015. The Sharing Economy: Why People Participate in Collaborative Consumption. Journal of the association for information science and technology. Forthcoming, 2015.

22. Hathaway, I. Muro, M. (2016, October 13). Tracking the gig economy: New numbers. [Online][Accessed at 08.05.2018]. Available at the WWW: https://www.brookings.edu/research/tracking-the-gigeconomy-new-numbers/

23. Hennig-Thurau, T., Henning, V. Sattler, H. 2007. Consumer file sharing of motion pictures. Journal of Marketing. 71(4). Pp: 1-18.

24. Hirschman, E. C. 1994. Consumers and their animal companions. Journal of Consumer Research. 20. Pp: 616-633

25. Huang, z. Benyoucef, M.2017. The effects of social commerce design on consumer purchase decision-making: An empirical study. Electronic Commerce Research and Applications. 25. P. 40-58

26. Kaplan, A.M., \& Haenlein, M. 2010. Users of the world, unite! The challenges and opportunities of Social Media. Business Horizons. 53(1). Pp: 59-68.

27. Kim, J. Yoon, Y. Zo, H. 2015. Why People Participate in the Sharing Economy: A Social Exchange Perspective. Pacific Asia Conference on Information Systems (PACIS)

28. Kim,S. Lee, K. Koo,C. Yang,S 2017. Examining the influencing factors of intention to share accommodations in online hospitality exchange networks. Journal of Travel \& Tourism Marketing. 35(1). P.16-31.

29. Matzner, M. Chasin,F. Todenhöfer, L.2015. To Share or Not to Share: Towards Understanding the Antecedents of Participation in IT-Enabled Sharing Services. Proceedings of Twenty-Third European Conference

30. Martin, C. J. 2016. The sharing economy: A pathway to sustainability or a nightmarish form of neoliberal capitalism. Ecological Economics. 121. Pp:149-159.

31. Mayer, R.C. Davis, J.H. Schoorman, F.D., 1995. An integrative model of organizational trust. Academy of management review. 20(3).Pp:709-734.

32. McDonagha,D. Brusebergb, A. Haslamc,C. 2002. Visual product evaluation: exploring users' emotional relationships with products. Applied Ergonomics. 33. Pp: 231-240

33. Mittendorf, C., 2018. Collaborative consumption: the role of familiarity and trust among millennials. Journal of Consumer Marketing, (just-accepted), pp.00-00. Muggea, E. Schoormansa, J. Hendrik, Schiffersteinb.H 2009.Emotional bonding with personalised products. Journal of Engineering Design. 20(5). Pp:467-476.

34. Olson, K. (2013). National Study Quantifies Reality of the "Sharing Economy" Movement. . [Online] [Accessed18/2/2018]. Available on the World Wide Web at:http://www.campbellmithun.com/678_national-study-quantifiesreality-of-the-sharing-economy-movement.

35. Owyang, Jermiah et al. (2013). The Collaborative Economy. Tech. rep. San Maeto, CA: Altimeter Group.

36. Oxford, "Sharing Economy," 2017. [Online] [Accessed7/2/2018]. Available on the World Wide Web at: https://en.oxforddictionaries.com/definition/sharing_economy

37. Prothero,A. Dobscha,S, Freund, J. Kilbourne,W. Luchs,M. Ozanne,L. Thøgersen,J 2011. Sustainable Consumption: Opportunities for Consumer Research and Public Policy. Journal of Public Policy \& Marketing. 30(1). pp. 31-38.

38. PwC. 2017 Infographic: The popularity of the collaborative economy. [Online][Accessed at 08.05.2018].Available at the WWW: https://www.digitalpulse.pwc.com.au/infographicpopularity-collaborative-economy/

39. Roh, T.2016. The sharing economy: Business cases of social enterprises using collaborative networks. Information technology and quantitative management. 91.pp $502-511$ 
40. Rubinstein, R. L., \& Parmelee, P. A. 1992. Attachment to place and the representation of the life course by the elderly. In I. Altman \& S. M. Low (Eds.), Place attachment (pp. 139-163). New York: Plenum.

41. Sable, P. 1995. Pets, attachments, and well-being across the life cycle. Social Work. 40.Pp: 334-341.

42. Sa'nchez, J. Callarisa, L. Rosa, M. Rodri'guez, R. Moliner, M.2006. Perceived value of the purchase of a tourism product. Tourism Management. 27.Pp:394-409

43. Schor, J.B. Fitzmaurice, C.J. 2015. Collaborating and Connecting: The emergence of the sharing economy. In L. Reisch \& J. Thogersen (eds.) Handbook on Research on Sustainable Consumption. Cheltenham, UK: Edward Elgar, forthcoming

44. Shimp, T. A. Madden, T. J. 1988. Consumer-object relations: A conceptual framework based analogously on sternberg's triangular theory of love. Advances in Consumer Research. 15. Pp: 163-168.

45. Stafford, L. 2008. Social exchange theories. In Engaging theories in interpersonal communication: Multiple perspectives (pp. 377-389.). SAGE Publications.

46. Stephen, A.T. Toubia, O. 2010. Deriving value from social commerce networks. Journal of Marketing Research. 47(2).Pp: 215-228.

47. The Economist. 2013. Peer-to-peer rental, the rise of the sharing economy On the internet, everything is for hire. March Edition. [Online] [Accessed 7/2/2018]. Available on the World Wide Web at: https://www.economist.com/news/leaders/21573104-internet-everything-hirerise-sharing-economy

48. Thomson, M. MacInnis, D. Park, W.2005. The Ties That Bind: Measuring the Strength of Consumers' Emotional Attachments to Brands. Journal of consumer psychology. 15(1).pp 77-91

49. Turel, O. Serenko, A.2012. The benefits and dangers of enjoyment with social networking websites. European Journal of Information Systems. 21.Pp: 512-528

50. Tussyadiah, I. P. 2015. An exploratory study on drivers and deterrents of collaborative consumption in travel. In Information and communication technologies in tourism 2015 (pp. 817-830). Switzerland: Springer International Publishing.

51. Yadav, M.S. Valck, K. de. Hennig-Thurau, T. Hoffman, D.L. Spann, M. 2013. Social commerce: a contingency framework for assessing marketing potential. Journal of Interactive Market. 27. pp. 311-323

52. Yaraghi, N. and Ravi, S., 2017. The current and future state of the sharing economy. Brookings India IMPACT Series No. 032017. March 2017. [Online][Accessed at 08.05.2018]. Available at the WWW: http://large.stanford.edu/courses/2017/ph240/carlton1/docs/032017.pdf

53. Van Der Heijden, H. 2004. User Acceptance of Hedonic Information Systems. MIS Quarterly. 28(4). Pp: 697-704.

54. Venkatesh, V. Thong,Y. Xu, X.2012. Consumer acceptance and use of information technology: extending the unified theory of acceptance and use of technology. MIS quarterly 36 (1).Pp: 157-178.

55. Venkatesh, V. Morris, M. Davis, G. Davis, F. 2003. User acceptance of information technology: toward a unified view. MIS Quartirly.27 (3). Pp: 425-478.

56. Wang, C. Zhang, P. 2012. The evolution of social commerce: The people, management, technology, and information dimensions. Communications of the Association for Information Systems. 31(1).Pp: 105-127. 